УДК 811.131.1'25

ББК 81.743.1-8

DOI: https://doi.org/10.17308/lic.2021.2/3415

\title{
ОСОБЕННОСТИ ПЕРЕВОДА РУССКОЙ РЕЛИГИОЗНОЙ ЛЕКСИКИ НА ИТАЛЬЯНСКИЙ ЯЗЫК
}

\author{
Е. В. Петрова \\ Воронежский государственный университет
}

\section{THE SPECIFICS OF TRANSLATING RUSSIAN RELIGIOUS VOCABULARY INTO ITALIAN}

\author{
E. V. Petrova \\ Voronezh State University
}

\begin{abstract}
Аннотация: по мере расширения культурных контактов и усиления взаимодействия между представителями различных христианских конфессий, в том числе православной и католической, отмечается и значительный рост интереса к русской религиозной литературе, в связи с чем возрастает потребность в точном и адекватном переводе текстов, относящихся к разным ее жанрам. В данной статье рассматриваются особенности перевода на итальянский язык отдельных единии русской религиозной лексики, в частности: 1) существительных, обозначающих абстрактные понятия; 2) существительных, именующих религиозных деятелей и лии иерковной иерархии; 3) прилагательных, употребляющуихся в функичи определений-эпитетов. В качестве методов исследования использованы метод структурно-семантического анализа и описательный метод. Практическим материалом исследования послужили оригинальный текст произведения неизвестного русского автора середины ХІХ в. "Откровенные рассказы странника духовному своему отиу» и текст его перевода на итальянский язык "Сапdidi racconti di un pellegrino al suo padre spirituale», выполненный М. Мартинелли. Основное внимание в работе уделяется лексико-семантическому анализу переводимого слова, а также анализу видов переводческих трансформаций, из которых наиболее частотными являются способ контекстуальной замень, транспозиция, описательный перевод с использованием ряда грамматических конструкций и транслитерация.
\end{abstract}

Ключевые слова: перевод, переводческая трансформация, лакуна, русский язык, итальянский язык, религиозный дискурс, религиозный текст.

\begin{abstract}
Orthodox and Catholic, increase, a rise in interest in Russian religious literature can be observed. Hence a need in accurate and adequate translation of texts related to different genres of such literature. This paper deals with the issue of specifics of translation of some Russian religious lexical units into Italian, in particular: 1) nouns denoting abstract notions; 2) nouns nominating religious personalities and persons in a church hierarchy; 3) adjectives used in the function of attributes and epithets. The main methods of research are structural and semantic analysis and a descriptive method. The research is based on the original text of an unknown Russian author of the middle of the XIXth century "Sincere Confessions of a Pilgrim to His Confessor" and its Italian translation "Candidi racconti di un pellegrino al suo padre spirituale" by M. Martinelli. Special attention is paid to lexical and semantic analysis of the translated word as well as to the analysis of the types of transformations used by a translator, the most frequent of which are contextual replacement, transposition, descriptive translation with some grammatical structures being used and transliteration.
\end{abstract}

Key words: translation, transformation in translation, lacuna, Russian language, Italian language, religious discourse, religious text.

(C) Петрова Е. В., 2021

Контент доступен под лицензией Creative Commons Attribution 4.0 License.

The content is available under Creative Commons Attribution 4.0 License. 


\section{Проблема определения понятия «религиозная лексика»}

Христианское вероучение является важнейшей составляющей историко-культурного наследия как русской, так и западноевропейской цивилизации. Религиозное мировоззрение как отдельных индивидуумов, так и целых народов, на протяжении многих столетий фиксировалось в языке, достигая высшей формы выражения в многочисленных произведениях литературного и философского творчества. По этой причине религиозно-церковная сфера бытования языка не могла не оказаться в центре внимания лингвистов. Первоначально исследования языка данной сферы проводились преимущественно в рамках функциональной стилистики (Л. П. Крысин, А. Д. Шмелев), постепенно смещаясь в область изучения религиозной лексики (К. А. Тимофеев, Р. И. Горюшина, А. М. Четырина, И. А. Королева) и религиозного дискурса (А. Д. Шмелев, В. И. Карасик, Е. В. Бобырева).

В последнее время по мере расширения контактов и усиления взаимодействия между представителями различных христианских конфессий, в том числе православной и католической, отмечается и значительный рост интереса к религиозной литературе самых разных жанров, а значит, возрастает потребность в точном и адекватном переводе текстов, относящихся к религиозному дискурсу, который Е. В. Бобырева определяет как «образование со сложной жанровой структурой, богатой системой ценностей и концептов, а также рядом специфических особенностей на языковом уровне» [1, с. 168]. Вопрос о выделении жанров религиозного дискурса на сегодняшний день остается дискуссионным. По мнению Е. В. Бобыревой, целесообразно выделять первичные речевые жанры - притчи, псалмы и молитвы как индивидуальные типизированные структурно-семантические и ценностные модели, и вторичные, представляющие собой интерпретацию и модификацию первых [Там же].

Отличительной особенностью произведения любого из жанров религиозного дискурса является наличие специальной лексики, номинирующей предметы и понятия религиозной сферы, зачастую не зафиксированные ни в двуязычных, ни в толковых словарях. По этой причине переводческая работа с литературой подобного рода предполагает не только знание структурно-семантических особенностей систем конфессиональной терминологии в переводящем языке и языке перевода, но и учет существующих в них различий при выборе способов перевода.

Однако само понятие «религиозная лексика» в современной лингвистике трактуется неоднозначно. Одни исследователи предпочитают рассматривать его в более широком аспекте, включая в него лексику, свойственную всем мировым религиям, и не только монотеистическим, другие понимают под ним исключительно лексику христианства или какой-либо из его конфессий. Другой не менее важной проблемой является проблема классификации лексических единиц религиозной сферы. Обычно таковые рассматриваются в рамках соответствующей тематической или лексико-семантической группы. Р. И. Горюшина относит тематические группы, включающие в себя лексику христианства, к терминологической лексике, и единицы той или иной тематической группы рассматриваются ею в качестве терминов. По мнению исследовательницы, религиозная лексика может быть распределена по следующим тематическим группам: 1) именования верховного божества; 2) наименования понятий, обозначающих религиозные начала; 3) наименования понятий, противоречащих религиозным началам; 4) наименования предметов культа, богослужений, религиозных обрядов и таинств; 5) именования священнослужителей христианской церковной иерархии; 6) именования подвижников и противников христианства; 7) наименования предметов церковной утвари и церковного обихода; 8) наименования религиозных праздников; 9) наименования книг церковного содержания [2].

При отборе лексических единиц для последующего анализа мы опирались на данную классификацию. Однако для наших целей не все девять пунктов приведенной классификации представляли одинаковый интерес. Наиболее важными и показательными с точки зрения переводческого анализа практического материала оказались пункты 2 и 6.

\section{Цель, предмет, материалы и методы исследования}

Целью настоящего исследования является анализ способов перевода единиц русской религиозной лексики на итальянский язык. Предметом исследования является русская и итальянская лексика религиозной сферы. Для достижения поставленной цели потребовалось решить следующие задачи: 1) выбрать из литературного источника на русском языке единицы, относящиеся к лексике православного христианства; 2) распределить отобранные лексические единицы по соответствующим тематическим группам; 3) выделить из общего корпуса примеров лексические единицы, представляющие, на наш взгляд, определенную трудность для перевода на итальянский язык; 4) проанализировать способы перевода указанных единиц на итальянский язык. Источником практического материала для данного исследования послужило произведение неизвестного автора середины XIX в. «Откровенные рассказы странника духовному своему отцу» и его перевод на итальянский язык «Candidi racconti di un pellegrino al suo padre spiri- 
tuale», выполненный М. Мартинелли. В качестве методов исследования были использованы: 1) метод структурно-семантического анализа интересующих нас лексических единиц; 2) описательный метод.

Как было сказано выше, на начальном этапе исследования из оригинального текста были отобраны лексические единицы, относящиеся к сфере православного христианства. Для удобства рассмотрения мы распределили данные лексические единицы на три группы по частям речи: а) существительные, обозначающие абстрактные понятия; б) существительные, именующие религиозных деятелей и лиц церковной иерархии; в) прилагательные, употребляющиеся в функции определений-эпитетов.

Следующим этапом работы стал анализ их семантических свойств и способов перевода на итальянский язык.

\section{Перевод существительных с абстрактным значением}

Из корпуса рассмотренных примеров были выделены лексические единицы, обладающие различным объемом семантического содержания в языке перевода и переводящем языке. Это такие существительные, как молитва, моление, богомыслие, прелесть, юродство.

1. Одной из наиболее часто встречающихся в русском тексте лексем является существительное «молитва», которое в тексте перевода имеет два соответствия: «orazione» и «preghiera»: «А что такое молитва? И как научиться молиться?» [3, с. 20]. - «Ма che cos' è l'orazione? E come s'impara a pregare?» [4, c. 31]. «...Это великое дело и почти невозможное для жителей мира достигнуть внутренней молитвы...» [3, c. 124]. - «Ma raggiungere l'orazione interiore è una grande impresa, quasi imposibile per un laico» [4, c. 111]. «...я отправился, шел и воссылал молитву мою с верой, упованием и благодарением к Отцу щедрот и всякого утешения...» [3, с. 156]. - «...ripresi il cammino innalzando la mia Preghiera con fede, abandono e riconoscenza verso il Padre di ogni consolazione....» [4, c. 132]. «...Ведь ты знаешь Иисусову молитву...» [3, c. 322]. - «Forse tu non conosci la Preghiera di Gesù....» [4, с. 187]. Как следует из анализа приведенных примеров оба итальянских существительных не являются полностью тождественными по смыслу, поскольку первое означает внутреннее мысленное сосредоточение, а второе - проговариваемое вслух обращение к Богу, часто в форме прошения. Электронный словарь Treccani следующим образом фиксирует различие между двумя этими терминами: «Per il suo carattere puramente interiore (per cui è detta anche o. mentale) [orazione] si suole distinguere dalla preghiera (o.vocale) che è accompagnata da manifestazione verbale» [5].
2. В русском языке скорее существует различие между понятиями «молитвенный текст», письменный или устный, и «внутреннее молитвенное действие». Так, автор русского текста несколько раз вместо слова «молитва» использует однокоренное отглагольное существительное «моление», обозначающее процесс действия: «Следовательно, единственный способ частого моления...» [3, с. 369]. - «Dunque, il solo metodo di orazione frequente...» [4, с. 121]. «Далее бесполезность одного устного моления можно видеть...» [3, с. 376]. - «Dove si dimostra la sterilità dell'orazione distratta e puramente esteriore» [4, c. 226].

3. Особую трудность для перевода представляют лексические единицы, образованные путем сложения корней, так называемые композиты. Указанные единицы являются преимущественно церковнославянскими по происхождению и, как правило, не имеют прямого соответствия в итальянском языке. Например, существительное «богомыслие». Его перевод осуществляется описательным способом с использованием конструкции существительное + предлог in + местоимение + предлог di + существительное: «...то есть словом Божиим, и соединением души с Богом, - богомыслием и непрестанной внутренней молитвой сердца» [3, с. 124]. - «...cioè la Parola di Dio, e l'unione con Dio nel raccoglimento in Lui del pensiero e nella incessante orazione del cuore...» [4, c. 110].

4. Существительное «прелесть» является перево-

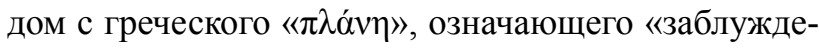
ние», «обман», «ложь» [6]. Однако одно из значений русского слова также «очарование», «привлекательность». Таким образом, оно совмещает в себе два противоположных, хотя и связанных значения, и в тексте перевода имеет два контекстуальных соответствия: «...ибо без этой проверки боялся, чтобы не впасть в прелесть и не принять естественных действий за благодатные...» [3, с. 38-39]. - «...temevo infatti che senza questa verifica sarei caduto nell'illusione di scambiare le azioni di natura per quelle della grazia...» [4, с. 46]. «Случалось и мне в странствии моем слыхать от людей набожных и ищущих спасения, что они боятся под изветом прелести коснуться внутреннего делания» [3, с. 406]. - «Ѐ capitato anche a me, nei miei pelligrinaggi, di sentir dire da gente devota, anelante alla salvezza, che teme di impegnarsi nella vita interiore per timore di suggestioni» [4, с. 249]. В последнем примере предпочтение отдано варианту «suggestione» вместо «illusione», поскольку «suggestione», помимо значения «внушение», «постороннее воздействие», имеет сему «привлекательность», будучи однокоренным с прилагательным «suggestivo» - заманчивый, чарующий. Таким образом, использование в данном контексте существительного «suggestione» позволяет актуализировать одно из значений переводимого 
русского слова «прелесть»: «внешне привлекательный характер заблуждения».

5. Имеются случаи перевода отдельных лексем путем транспозиции, замены одной части речи другой: «Ты, должно быть, из хорошего рода и только напускаешь на себя юродство ${ }^{1} »[3$, с. 128]. - «Devi essere di buone origini, e fingeti un semplice» [4, c. 113]. В приведенном примере абстрактное существительное, со всем присущим ему набором значений, заменяется прилагательным с конкретным окказиональным значением, реализуя свой прагматический потенциал, но утрачивая при этом ряд важных смыслов и коннотаций.

\section{Перевод существительных, представляющих собой именования религиозных деятелей и лиц церковной иерархии}

Из всего корпуса проанализированной лексики наиболее частотными в тексте являются конкретные однословные существительные, наименования церковных и религиозных деятелей, образованные суффиксальным и приставочно-суффиксальным способами, не всегда имеющие готовые словарные соответствия в итальянском языке. Это такие слова, как угодник, молитвенник, безмолвник, подвижник, келейница, старец.

1. Существительное «угодник», которое «Малый академический словарь русского языка» определяет как «святой, угодивший богу безгрешной, непорочной жизнью» [8], имеет в итальянском языке следующие соответствия: beato, santo [9]. При этом для перевода формы множественного числа, фигурирующей в более широком контексте, переводчиком выбрано слово «santi», а для формы единственного числа «servo». Подобный выбор, вероятно, обусловлен тем, что существительное «servo» в большей степени актуализирует значение «самоотверженное личное служение человека Богу», имеющееся у слова «угодник»: «Пойду прежде всего в Киев, поклонюсь угодникам Божиим...» [3, с. 106]. - «Andrò prima di tutto ai santuari di Kiev, e pregherò in ginocchio ai Santi di Dio...» [4, с. 97]. «...вот живое слово угодника Божия...» [3, с. 127]. - «Ecco, disse, la parola viva del servo di Dio...» [4, c. 112].

2. Для перевода существительного «подвижник» используются два термина «atleta dello spirito» и «asceta»: «Ее написали не простые греческие монахи, а древние великие и святейшие люди... Марк Подвижник...» [3, с. 93]. - «...non l'hanno scritto comuni monaci greci, ma grandi santissimi uomini del tempo andato come ...Marco l'Atleta dello spirito...» [4, c. 87]. «Послушай, что пишет Марк Подвижник» [3, с. 315]. - «Senti quello che scrive Marco l'Asceta». [4, c. 182].
Несмотря на наличие в западно-христианской традиции двух регулярных соответствий переводимому термину, в одном случае переводчик предпочел прибегнуть к транслитерации с последующим комментарием: «Рассказывал он о святой Афонской горе, о великих подвижниках и о многих отшельниках и затворниках» [3, с. 307]. - «Mi parlò dell'Athos, la Santa Montagna, dei suoi grandi podvizniki* e dei molti eremiti e anacoreti». «*da podvig, che significa «impresa». Termine attribuito a coloro che raggiungono una intensa vita ascetica e una eccezionale concentrazione della preghiera. Nel linguaggio spirituale dell'Occidente lì si direbbe atleti dello spirito (выделено нами. - E. П.)» $[4, \text { c. } 176]^{2}$. Если использование двух синонимичных терминов «atleta dello spirito» и «asceta» можно объяснить стремлением избежать языкового однообразия, то перевод с помощью транслитерации может быть продиктован желанием подчеркнуть конфессиональный и этнический характер описываемого явления.

В этой связи возникает вопрос о допустимости перевода конфессионально маркированного термина при помощи его аналога из другой традиции. В решении этого вопроса автор перевода не придерживается единой стратегии: «Матушка игуменья оставила меня у себя при келии и постригла» [3, с. 157]. - La madre superiora mi accolse nella sua cella e mi indusse a prendere i voti» [4, с. 133]. «...настоятель добрейший, богомольный и странноприимный...» [3, с. 15]. - «...un abate molto caritatevole, devoto e ospitale...» $[4$, c. 27]. Хотя в словарной статье «настоятель» приводятся следующие варианты: 1. (игумен) superiore (spec. di convento) 2. (церкви) parroco; в статье «настоятельница», соответственно, superiora [7; 9]. В своем первичном значении «вышестоящий, начальствующий» прилагательное «superiore» имеет широкую сферу употребления и, следовательно, не несет какой-либо специфической коннотации. Вариант же «abate» не получил распространения за рамками западнохристианской традиции, и использование данного термина в отношении православного иерарха воспринимается, скорее, как адаптация.

3. При переводе следующих существительных автор прибегает к описательному способу с использованием грамматических конструкций, таких как артикль + союз сhе + глагол: «Я подумал, не молитвенник ли он...» [3, с. 140]. - «Quello, pensai, è uno che prega» [4, с. 121]; местоимение + союз сhе +глагол + предлог in + существительное: «...ибо наблюдательный безмолвник...» [3, с. 410]. - «Poiché colui che vigila nel silenzio...» [4, с. 252]; местоимение + союз сhе + глагол + существительное: «...влияние безмолвника на ближних...» [3, c. 411] - «...l'influsso sul prossimo di colui che osserva il silenzio...» [4, c. 253];

${ }^{1}$ Подробнее об этом см.: [7, p. 133-148].

${ }^{2}$ Подробнее об этом см.: [7, p. 142-143]. 
или сущеествительное + союз сhе + глагол + предлог in + существительное: «Она вышла к ним, а меня оставила с монахинями, ее келейниц̧ами...» [3, с. 157]. - «...Ella andò loro incontro e mi lasciò con le monache che la assistevano in cella ${ }^{3} . . . »[4$, c. 133]; а также прилагательное + союз сhе + глагол + предлог in +сушествительное: «Уединенный безмолвник не только не находится в бездейственном и праздном состоянии....» [3, с. 410]. - «Il solitario che vive nel silenzio non solo non si trova in una condizione di inattività e di ozio...» $[9$, p. 253].

4. Одна и та же лексическая единица может быть переведена в одном случае при помощи окказионального соответствия, в другом - путем транслитерации: «...и я не знал, как благодарить Бога за то, что Он мне, такому окаянному грешному, послал такого спасительного старияа и наставника...» [3, с. 33]. «...e non sapevo come ringraziare Iddio di aver mandato, a un peccatore ormai perduto quale io sono, la salvezza di un maestro e un guida...» [4, с. 42]. В данном примере мы наблюдаем прием смыслового развития: определенные внутренние качества и способности старого человека позволяют ему быть учителем maestro. Такое решение дает возможность, с одной стороны, избежать буквализма, с другой - чрезмерного использования транслитерации. Тем не менее в следующем примере и далее на протяжении всего текста для именования конкретного персонажа применяется именно этот прием: «Стареи перекрестился и начал говорить...» [3, с. 18]. - «Lo starets si fece il segno della croce e prese a dire...» [4, с. 30]. То есть автор перевода следует стратегии, о которой говорилось в предыдущем параграфе - передавать путем транслитерации обозначения некоторых культурноисторических реалий страны, предметов русского церковного обихода и некоторых традиций русского православия, сопровождая перевод комментарием.

\section{Перевод определений-эпитетов богомудрый, богобоязненный, набожный, богомольный, благочестивый, окаянный}

Данную группу составляют прилагательные церковнославянского происхождения, образованные путем сложения, использующиеся в качестве характеристики того или иного лица.

1. Прилагательное «богомудрый» имеет два варианта перевода. В одном случае это перевод с помощью частичного эквивалента, причастия «ispirato»«вдохновенный», в другом - с использованием грамматической конструкции предлог in + cyus. saggezza: «Но недолго я пользовался наставлениями

${ }^{3}$ Хотя электронный словарь Treccani как приводит формы мужского рода «cellerario» и «celleraio» от позднелатинского «cellararius» и средневекового «cellerarius», так и указывает на наличие формы женского рода: la madre c., la c. [5]. моего любезного и богомудрого старца...» [3, с. 33]. - «Ma non potei giovarmi a lungo del mio amato e ispirato staretz» [4, с. 42]. «Древние богомудрые отцы наши одерживали над унынием победу...» [3, c. 408]. - «...gli antichi Padri, nella loro saggezza, ottennero la vittoria sullo sconforto...» [4, c. 251].

2. Прилагательное «богобоязненный» в одном случае переведено как «devoto»: «Один богобоязненный человек посоветовал ему...» [3, с. 49]. - «Un uomo devoto gli consigliò...» [4, c. 54]; в другом - с использованием грамматической конструкции причастие + предлог di + существительное: «...но даже и от некоторых богобоязненных мирян приходится слышать...» [3, с. 400]. - «...ma anche fra i laici timorati di Dio, capiti spesso di udire...» [4, c. 244].

Стоит отметить, что одним из наиболее частотных итальянских соответствий для целого ряда русских прилагательных в функции определений-эпитетов выступает прилагательное «devoto», имеющее следующие значения: 1) преданный, посвятивший себя чему-либо, кому-либо; 2) набожный, религиозный, верующий. «Случалось и мне в странствии моем слыхать от людей набожных и ищущих спасения...» $[3$, c. 406$]$. - «E capitato anche a me, nei miei pelligrinaggi, di sentir dire da gente devota, anelante alla salvezza... » [4, c. 249]. Оно же используется и для перевода прилагательного «богомольный»: «...настоятель добрейший, богомольный и странноприимный...» [3, c. 15]. - «...un abate molto caritatevole, devoto e ospitale...» [4, с. 27]. Имеются случаи его употребления в субстантивированной форме: «У нас, говорил, странников принимают, успокаивают вместе с богомольцуами на гостинице» [3, с. 17]. - «Noi accogliamo i pellegrini e li ospitiamo nella forresteria con $i$ devoti»» [4, c. 29]. При помощи этого же прилагательного переводится и термин «благочестивый»: «Мы с благочестивым спутником профессором не смогли преодолеть общего желания, чтобы отправиться в путь...» [3, с. 398]. - «Né io, né il mio devoto compagno di viaggio, il professore abbiamo saputo vincere il desiderio, prima di riprendere il cammino...» [4, c. 243]. Таким образом, при отсутствии прямых эквивалентов для целого ряда русских лексем средством решения проблемы становится использование итальянского прилагательного с широким спектром значений, имплицитно включающего в себя те оттенки значений, которые дифференцируются переводимыми русскими прилагательными.

3. Для широкоупотребительного в русской народной речи позапрошлого века определения-эпитета «окаянный» имеется четыре соответствия ${ }^{4}$. В тексте перевода используются сочетания «ресcatore pentito», «peccatore ormai perduto», «inguaribile peccatore».

${ }^{4}$ Подробнее об этом см.: [9, p. 114-115]. 
Каждое из них имеет собственный семантический оттенок, подчеркивающий тот или иной аспект внутреннего состояния грешника: раскаяние, безнадежность, осознание непоправимости собственной участи, актуализирующийся переводчиком в зависимости от контекста. «...поблагодарив его за отеческое учение меня окаянного...» [3, с. 34]. - «...ringraziandolo per l'insegnamento paterno che aveva dato a me, peccatore pentito ...» [4, с. 42]. «...и я не знал, как благодарить Бога за то, что Он мне, такому окаянному грешному, послал такого спасительного старца и наставника...» [3, с. 33]. - «... е non sapevo come ringraziare Iddio di aver mandato, a un peccatore ormai perduto quale io sono, la salvezza di un maestro e un guida...» [4, с. 42]. «Помолитесь о мне, окаянном грешнике...» [3, с. 168]. - «Pregate per me, inguaribile peccatore...» [4, с. 140].

Однако для перевода словосочетания «окаянная душа» используется прилагательное «sciagurato», имеющее значения: 1) несчастный; 2) злобный, злодейский. «По грехам ли окаянной души моей...» [3, c. 40]. - «...forse per i peccati che pesavano sulla mia anima sciagurata...» [4, с. 47].

Как следует из приведенных примеров, в данном случае подбор эквивалента осуществляется путем конкретизации значения переводимого слова.

\section{Заключение}

В результате проведенного анализа выявлено, что среди единиц русской религиозной лексики, использующихся в тексте оригинала, значительную часть составляют:

- однословные термины, являющиеся именованиями христианских подвижников и лиц православной церковной иерархии;

- сложные существительные, номинирующие абстрактные религиозные понятия;

- производные от них прилагательные.

Отсутствие в итальянском языке прямых соответствий для значительного количества указанных лексических единиц свидетельствует о том, что в системах конфессиональной терминологии русского и итальянского языков имеются определенные структурно-семантические различия, которые необходимо учитывать при переводе единиц данной сферы.

В процессе анализа итальянского текста выявлено, что наиболее частотные способы перевода единиц русской религиозной лексики следующие.

1. Контекстуальная замена переводимого русского слова итальянским словом с более общим либо с более узким значением.

2. Транспозиция.

Перевод безэквивалентной лексики нередко осуществляется описательным способом с применением следующих грамматических конструкций: а) существительное + предлог іп + сущчествительное + предлог di + существительное;

б) артикль + союз сhе + глагол;

в) местоимение + союз che + глагол + предлог in + существительное;

г) существительное + союз сhе + глагол + предлог іп + существительное;

д) местоимение + союз che + глагол + сущуествительное;

е) прилагательное + союз сhе + глагол + предлог in + существительное;

ж) причастие + предлог di + существительное;

3) предлог in + существительное;

3. Перевод путем транслитерации.

Выявленные виды переводческих трансформаций требуют дальнейшего подробного изучения и систематизации с привлечением более обширного корпуса примеров, результатом чего могла бы стать разработка практических приемов и рекомендаций для перевода русской лексики религиозной сферы.

\section{ЛИТЕРАТУРА}

1. Бобырева Е. В. Религиозный дискурс : ценности и жанры // Проблемы филологии, культурологии и искусствоведения. Волгоград, 2008. № 1. С. 163-168.

2. Горюшина Р. И. Лексика христианства в русском языке (системные отношения прямых конфессиональных и производных светских значений слов) : дис. ... канд. филол. наук. Волгоград, 2002. 179 с.

3. Откровенные рассказы странника своему духовному отцу. М. : Даръ, 2005. 448 с.

4. Шмелев А. Д. Языковые особенности различных видов религиозного дискурса // Язык в движении : к 70-летию Л. П. Крысина / отв. ред. Е. А. Земская, М. Л. Каленчук. М. : Языки славянской культуры, 2007. C. 612-621.

5. Vocabolario Treccani. URL: http://www.treccani.it

6. Королева И. А. Православная сакрально-богослужебная лексика в современном русском языке и в художественном тексте : дис. ... канд. филол. наук. Волгоград, 2013. $186 \mathrm{c.}$

7. Ferro $M$. Ch. Tradurre i lemmi russi appartenenti al lessico agiografico slavo ecclesiastico. Difficoltà e proposte. Studi Slavistici IX, 2012. P. 133-148.

8. Словарь русского языка : в 4 т. / РАН, Ин-т лингвистич. исследований ; под ред. А. П. Евгеньевой. 4-е изд. стер. М. : Рус. яз. : Полиграфресурсы, 1999. T. IV. С-Я. 797 c.

9. Ferro M. Ch., Romoli F. Un lexicon slavo ecclesistico-russo-italiano dei termini religiosi e filosofico-teologici. Presentazione del proggetto e primi risultati con commenti degli attributi del diavolo // Stephanos. 2014. No. 7. P. 96121.

10. Candidi racconti di un pellegrino al suo padre spirituale. Traduzione di M. Martinelli. VII edizione, Tascabili Bompiani, 2012. 368 p. 


\section{REFERENCES}

1. Bobyreva E. V. Religioznyj discurs: zennosti i zhanri. In: Problemi filologii, kultutologii i iskusstvovedenia. Volgograd, 2008. No. 1. Pp. 163-168.

2. Goriushina R. I. Leksika khristianstva v russkom jazike: (sistemnyje otnoshenija priamykh pronfessionalnych znachenij i proizvodnykh svetskikh znachenij slov): diss. kand. filol. nauk. Volgograd, 2002. 179 p.

3. Otkrovennyje rasskazy strannika svojemu dukhovnomu otsu. M.: Dar, 2005. 448 p.

4. Šmelev A. D. Jazikovyje ossobennosti razlichnykh vidov religioznogo diskursa. In: Jazik v dvizhenii: $k$ 70-letiju L. P. Krysina / otv. red. E. A. Zemskaja, M. L. Kalenchuk. M.: Jazyki slavianskoj kul'tury. 2007. Pp. 612-621.

5. Vocabolario Treccani. Available at: http://www.treccani.it

Воронежский государственный университет

Петрова Е. В., доиент кафедры романской филологии

E-mail:petrova@rgph.vsu.ru

Поступила в редакичюю 1 марта 20212.

Принята к публикации 22 марта 2021 2.

\section{Для цитирования:}

Петрова Е. В. Особенности перевода русской религиозной лексики на итальянский язык // Вестник Воронежского государственного университета. Серия: Лингвистика и межкультурная коммуникация. 2021. № 2 . C. 56-62. DOI: https://doi.org/10.17308/lic.2021.2/3415
6. Koroleva I. A. Pravoslavnaja sakral'no-bogosluzhebnaja leksika $\mathrm{v}$ russkom jazike y khudozhestvennom tekste: diss. kand. filol. nauk. Volgograd, 2013. 186 p.

7. Ferro M. Ch. Tradurre i lemmi russi appartenenti al lessico agiografico slavo ecclesiastico. Difficoltà e proposte. Studi Slavistici IX, 2012. Pp. 133-148.

8. Slovar' russkogo jazyka. V 4 t. / RAN, institute lingvistich. issledovanij; pod red. A. P. Evgenijevoj. 4-e izd. ster. M.: Rus. jaz.: Poligrafresursy, 1999. T. IV. С-Я. 797 p.

9. Ferro M. Ch., Romoli F. Un lexicon slavo ecclesistico-russo-italiano dei termini religiosi e filosofico-teologici. Presentazione del proggetto e primi risultati con commenti degli attributi del diavolo. In: Stephanos. 2014. No. 7. Pp. 96-121.

10. Candidi racconti di un pellegrino al suo padre spirituale. Traduzione di M. Martinelli. VII edizione, Tascabili Bompiani, 2012. 368 p.

Voronezh State University

Petrova E. V., Associate Professor of the Romanic Philology Department

E-mail:petrova@rgph.vsu.ru

Received: 1 March 2021

Accepted: 22 March 2021

\section{For citation:}

Petrova E. $V$. The specifics of translating Russian religious vocabulary into Italian. Proceedings of Voronezh State University. Series: Linguistics and Intercultural Communication. 2021. No. 2. Pp. 56-62. DOI: https://doi.org/10.17308/ lic. $2021.2 / 3415$ 